\title{
Amino acid feeding reduces ammonia production through rearrangement of metabolic fluxes in central carbon metabolism of $\mathrm{CHO}$ cells
}

\author{
Iman Shahidi Pour Savizi ${ }^{1}$, Nader Maghsoudi ${ }^{2}$, Ehsan Motamedian ${ }^{1}$, Nathan E. Lewis ${ }^{3}$, \\ and Seyed Abbas Shojaosadati ${ }^{1}$ \\ ${ }^{1}$ Tarbiat Modares University \\ ${ }^{2}$ Shahid Beheshti University of Medical Sciences \\ ${ }^{3} \mathrm{UCSD}$
}

September 24, 2021

\begin{abstract}
Ammonia is a toxic byproduct of $\mathrm{CHO}$ cell metabolism, which inhibits cell growth, reduces cell viability, alters glycosylation, and decreases recombinant protein productivity. In an attempt to minimize the ammonium accumulation in cell culture media, different amino acids were added individually to the culture medium before the production phase to alleviate the negative effects of ammonium on cell culture performance. Among all the amino acids examined in this study, valine showed the most positive impact on $\mathrm{CHO}$ cell culture performance. When the cultured $\mathrm{CHO}$ cells were fed with $5 \mathrm{mM}$ valine, EPO titer was increased by $25 \%$ compared to the control medium, and ammonium and lactate production were decreased by 23 and $26 \%$, respectively, relative to the control culture. Moreover, the sialic acid content of the EPO protein in valine-fed culture was higher than in the control culture, most likely because of the lower ammonium concentration. Flux balance analysis (FBA) results demonstrated that the citric acid cycle was enriched by valine feeding. The analysis revealed that there might be a link between promoting tricarboxylic acid (TCA) cycle metabolism in valine-fed culture and reduction in lactate and ammonia accumulation. Furthermore, in valine-fed culture, FBA outcomes showed that alanine was excreted into the medium as the primary mechanism for reducing ammonium concentration. It was predicted that the elevated TCA cycle metabolism was concurrent with an increment in recombinant protein production. Taken together, our data demonstrate that valine addition could be an effective strategy for mitigating the negative impacts of ammonium and enhancing glycoprotein production in both quality and quantity.
\end{abstract}

\section{Hosted file}

Main Script Amino Acid Feeding.docx available at https://authorea.com/users/413471/articles/ 538610-amino-acid-feeding-reduces-ammonia-production-through-rearrangement-of-metabolicfluxes-in-central-carbon-metabolism-of-cho-cells 

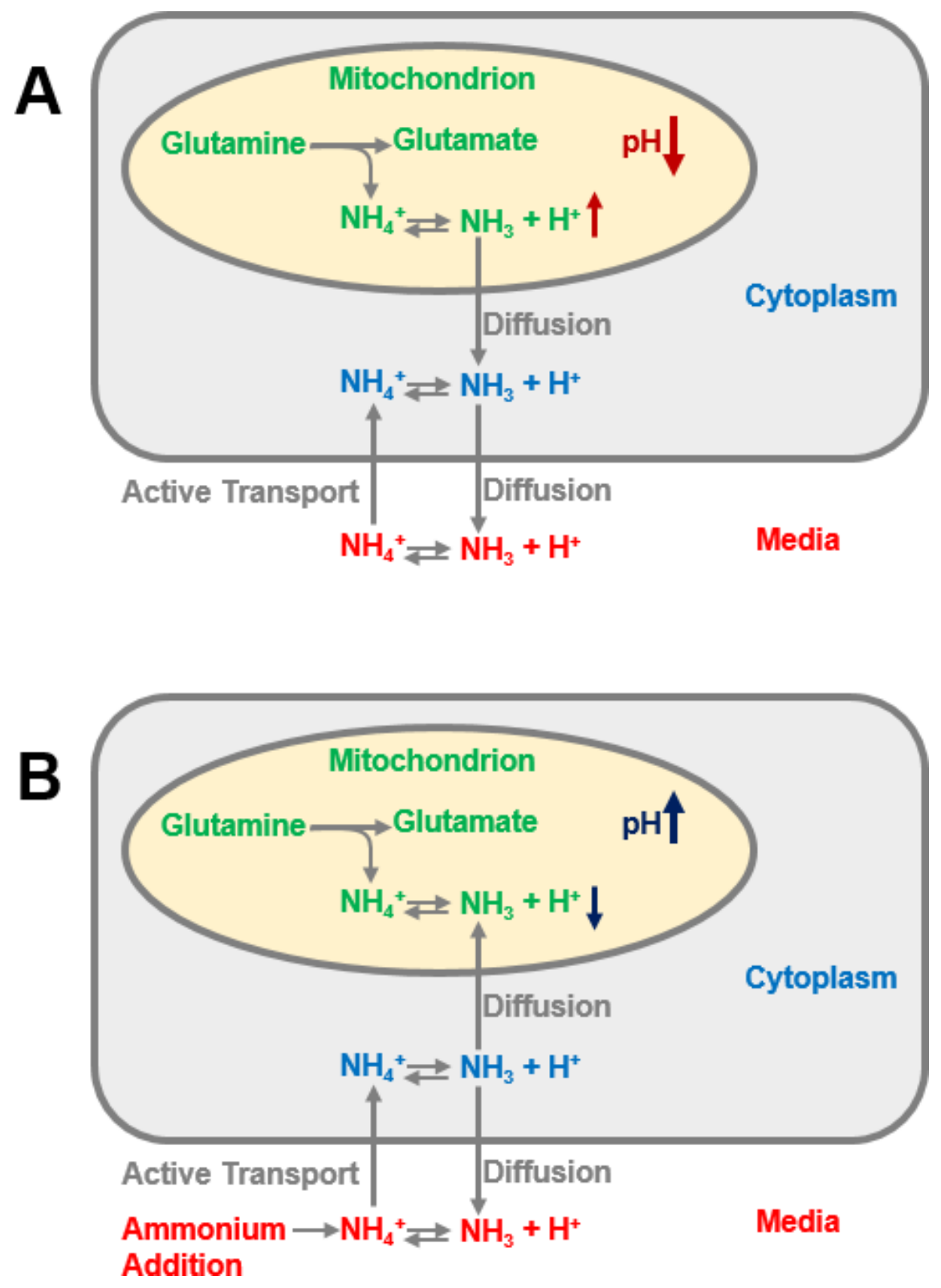

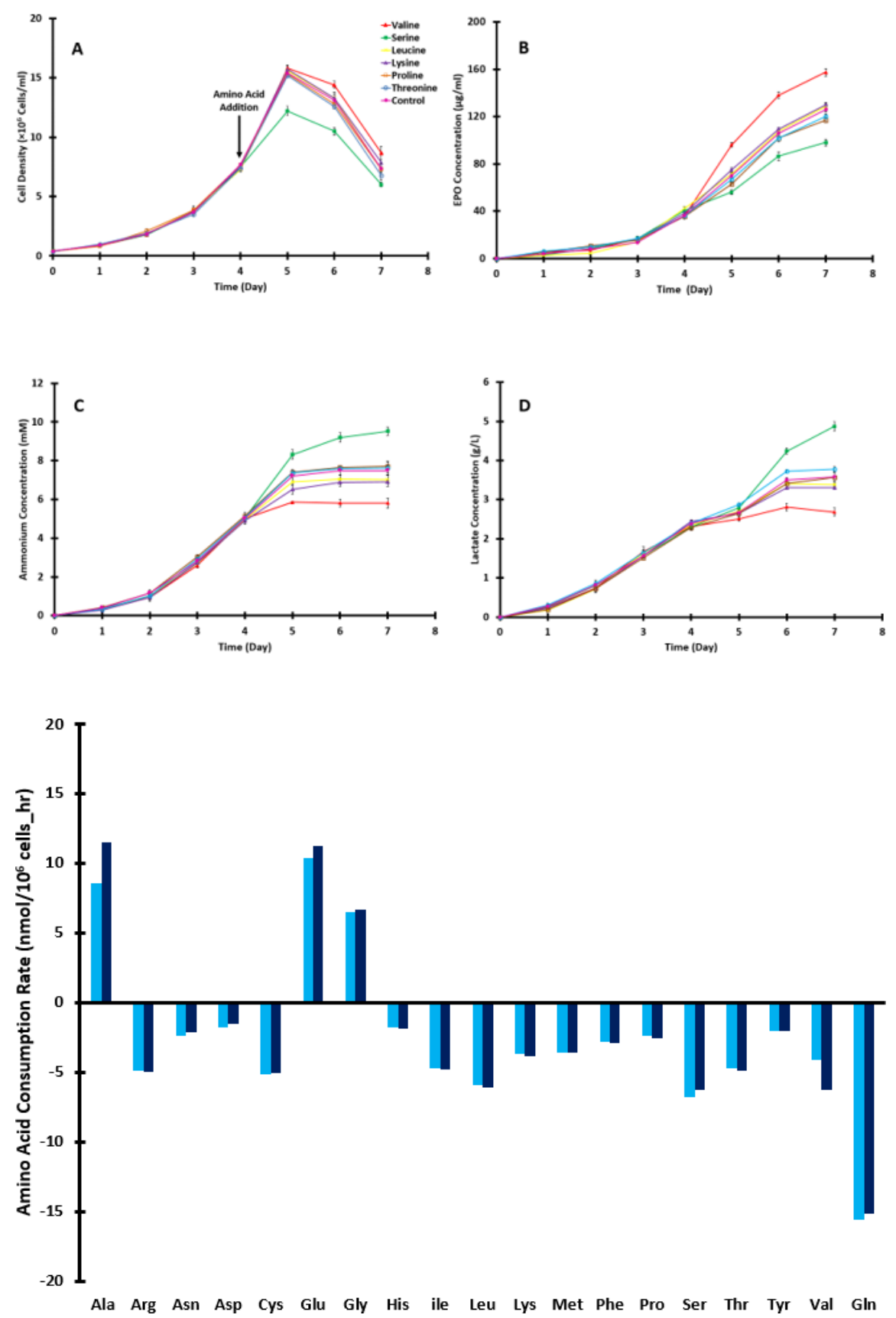

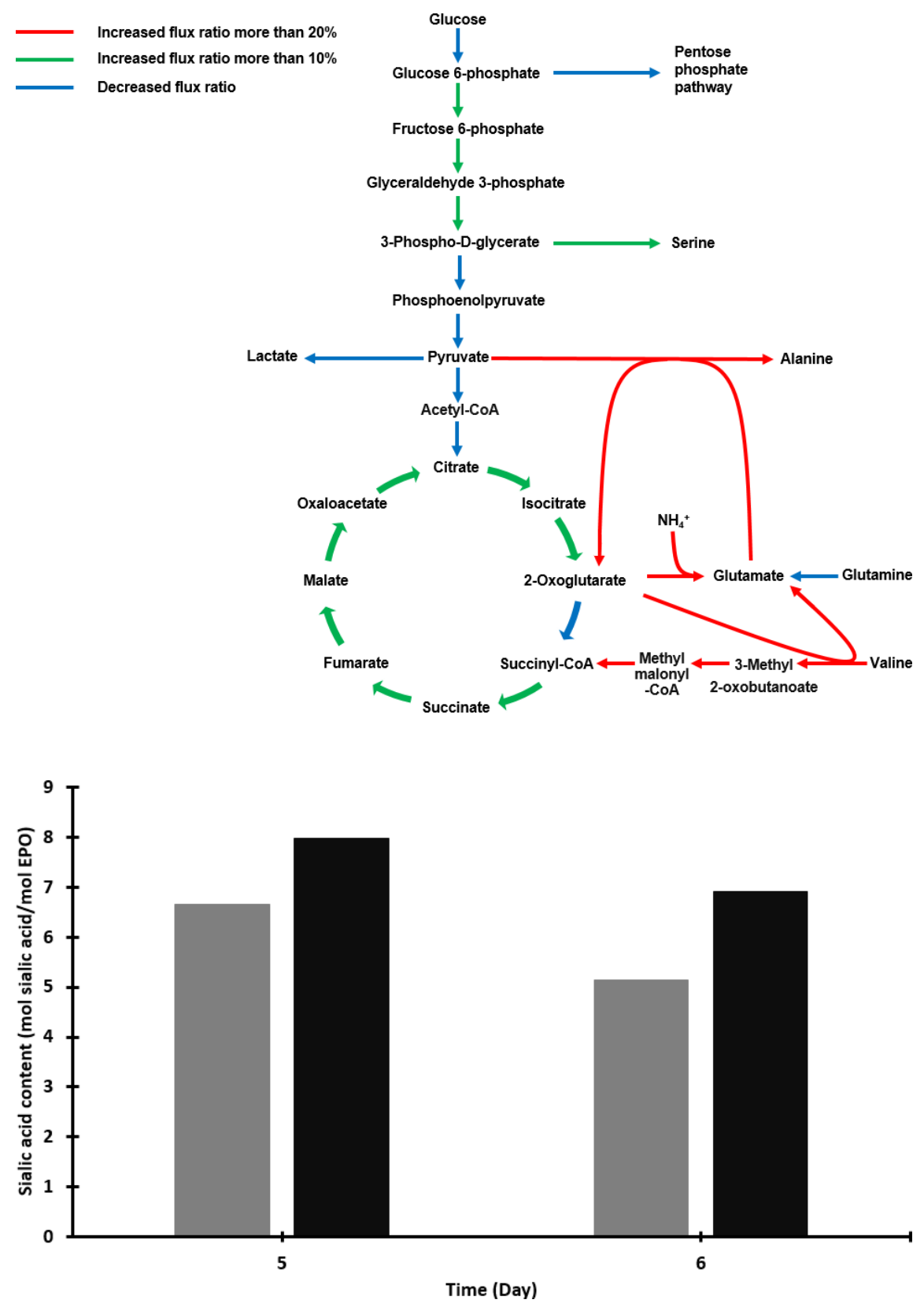